\title{
BMJ Open Risk factors associated with Richter's transformation in patients with chronic lymphocytic leukaemia: protocol for a retrospective population-based cohort study
}

\author{
Mariam Hussein Hleuhel, ${ }^{1}$ Yasmin Ben-Dali, ${ }^{1}$ Caspar Da Cunha-Bang, \\ Christian Brieghel, ${ }^{1}$ Erik Clasen-Linde, ${ }^{2}$ Carsten Utoft Niemann, ${ }^{1}$ \\ Michael Asger Andersen ${ }^{1}$
}

To cite: Hleuhel MH, BenDali Y, Da Cunha-Bang C, et al. Risk factors associated with Richter's transformation in patients with chronic lymphocytic leukaemia: protocol for a retrospective populationbased cohort study. BMJ Open 2019;9:e023566. doi:10.1136/ bmjopen-2018-023566

- Prepublication history for this paper is available online. To view these files, please visit the journal online (http://dx.doi. org/10.1136/bmjopen-2018023566).

MHH and YB-D contributed equally.

MHH and YB-D are coauthorship. CUN and MAA are co-senior authors.

Received 18 April 2018

Revised 28 November 2018

Accepted 29 November 2018

D) Check for updates

(C) Author(s) (or their employer(s)) 2019. Re-use permitted under CC BY-NC. No commercial re-use. See rights and permissions. Published by BMJ.

For numbered affiliations see end of article.

\section{Correspondence to} Carsten Utoft Niemann; Carsten.utoft.niemann@regionh. $\mathrm{dk}$

\section{ABSTRACT}

Introduction Richter's transformation (RT) refers to the development of an aggressive lymphoma in patients with chronic lymphocytic leukaemia (CLL) or small lymphocytic lymphoma. Studies have shown that 2-10\% of patients with CLL develop RT including diffuse large B-cell lymphoma (DLBCL) and less common Hodgkin lymphoma ( $\mathrm{HL})$. This study aims to assess the risk factors for RT of CLL in a nationwide cohort. Additionally, we want to examine prognostic factors in patients with RT. These findings may guide management of treated as well as untreated patients with CLL in the risk of RT.

Methods Clinical data for patients diagnosed with CLL between 2008 and 2016 will be retrieved from the Danish National CLL registry (DCLLR). Using the Danish unique person identification number, clinical data will be merged with histologically verified DLBCL and/or HL diagnoses retrieved from the Danish National Pathology Data Bank. This will ensure complete follow-up for all patients. The DCLLR includes data from more than 4000 patients with CLL ensuring a median follow-up of 3 years. With the reported incidences (2-10\%) of RT, we expect to identify 80-200 CLL patients with RT enabling analysis of overall survival following RT. From time of CLL diagnosis, estimates of cumulative incidence of RT will be calculated using the Aalen-Johansen estimator. From time of RT diagnosis, survival analysis will be performed by KaplanMeier method. Cox proportional hazards models will be used for multivariable survival analysis.

Ethics and dissemination Approvals for data collection and analysis was obtained from the Danish Data Protection Agency and the Danish Health Authorities. All data will be managed confidentially according to guidelines and legislation. The dissemination will include a publication of scientific papers and/or presentations of the study findings at international conferences.

\section{INTRODUCTION}

Chronic lymphocytic leukaemia (CLL) is the most common form of leukaemia in adults. ${ }^{1}$ Approximately 400 people are

\section{Strengths and Limitations}

- Largest study to date on Richter's transformation (RT) including a nationwide cohort of approximately 4000 CLL patients with an expected prevalence of 80-200 RT patients.

- Multivariable models of risk factors will be performed.

- Predefined analyses according to published protocol.

- Methodological challenges to conduct research in this area.

- Confounding effects of socioeconomic status, ethnical, dietary and geographical differences on RT development will not be adjusted for.

diagnosed with CLL in Denmark each year with increasing incidence. ${ }^{2}$ CLL is characterised by a heterogeneous disease course where some patients require initial treatment, while about $40 \%$ remain untreated. ${ }^{2}$ Patients with CLL can be stratified into four different risk groups: Low, intermediate, high or very high risk based on the CLL international prognostic index. ${ }^{2}$ Despite an improved prognosis following the introduction of chemo-immunotherapy and targeted therapy, ${ }^{1}$ Richter's transformation (RT) still affects about $2 \%-10 \%$ of patients with CLL. ${ }^{3-5}$

RT, defined as the transformation of CLL or small lymphocytic lymphoma into an aggressive lymphoma (diffuse large B-cell lymphoma (DLBCL) or Hodgkin's lymphoma (HL) ) is one of the most severe complications associated with CLL. ${ }^{3467}$ The median time from the CLL diagnosis until RT occurs to lie in the range of 2-4years, but some patients are diagnosed with RT concomitant with CLL. ${ }^{378}$ Rarely, some patients are diagnosed with RT at the time of CLL diagnosis. ${ }^{1}$ The 
Table 1 Summary of the included possible risk factors

\begin{tabular}{|c|c|}
\hline Demographical & $\begin{array}{l}\text { Gender (male) } \\
\text { Age (>65years) }\end{array}$ \\
\hline Clinical & $\begin{array}{l}\text { Advanced binet stage }(\mathrm{B} / \mathrm{C}) \\
\text { CLL-IPI score }(>1) \\
\text { B-symptoms (unintentional weight loss, extensive tiredness, fever }\left(>38.0^{\circ} \mathrm{C}\right) \text {, night sweats) } \\
\text { Lymphadenopathy (size (diagonal measure, } \mathrm{cm}), \text { number of lymph nodes and number of nodal areas) } \\
\text { Splenomegaly }(>12 \mathrm{~cm}) \\
\text { ECOG-PS }(>1) \\
\text { Smoking status (yes/no) } \\
\text { Comorbidities (CIRS and CCI) }\end{array}$ \\
\hline Genetic/Biological & $\begin{array}{l}\text { Del(13q) absence, normal FISH } \\
\text { Tri12 } \\
\text { Del(11q) } \\
\text { Del(17p) } \\
\text { TP53 mutation status } \\
\text { CDKN2A and NOTCH1 mutation status } \\
\text { Unmutated IGHV status ( } \geq 98 \text { germline identity) } \\
\text { CD38, CD49d, ZAP-70 positivity (Population }>30 \% \text { positive) } \\
\text { Ki-76, C-MYC, PAX-5, BcL-2, Bcl-6, CD79-a, MUM-1 positivity on pathology samples following RT } \\
\text { DLBCL subtype (GCB or ABC) }\end{array}$ \\
\hline Biochemical $^{21}$ & $\begin{array}{l}\text { Haemoglobin }(<10 \mathrm{~g} / \mathrm{dl}) \\
\text { Platelet count }\left(<100 \times 10^{9} / \mathrm{L}\right) \\
\text { Peripheral blood leucocytes }\left(>8,810^{9} / \mathrm{L}\right) \\
\text { Peripheral blood lymphocytes }\left(5 \times 10^{9} / \mathrm{L}\right) \\
\text { Peripheral blood neutrophils }\left(<2.25 \times 10^{9} / \mathrm{L}\right) \\
\beta-2-\text { microglobulin elevation }(>4 \mathrm{mg} / \mathrm{Lng} / \mathrm{mL}) \\
\text { Lactate dehydrogenase elevation }(>205 \mathrm{U} / \mathrm{L}) \\
\text { Abnormal levels of immunoglobulins }(\mathrm{lgM}, \operatorname{lgG}, \operatorname{lgA})\end{array}$ \\
\hline Treatment-related & $\begin{array}{l}\text { CLL-treatment regimens } \\
\text { Chemoimmunotherapy (purine-nucleoside analogue and/or alkylating agents plus/minus monoclonal } \\
\text { antibody therapy and/or kinase inhibitor therapy) } \\
\text { Stem cell transplantation } \\
\text { Radiation therapy } \\
\text { RT-treatment regimens } \\
\text { Chemoimmunotherapy (purine-nucleoside analogue and/or alkylating agents plus/minus monoclonal } \\
\text { antibody therapy and/or kinase inhibitor therapy) } \\
\text { Stem cell transplantation } \\
\text { Radiation therapy }\end{array}$ \\
\hline
\end{tabular}

ABC, activated B-cell-like; CCI, Charlson Comorbidity Scoring System; CDKN2A, cyclin-dependednt kinase Inhibitor 2A; CD38, cluster of differentiation 38; CD79-a, cluster of differentiation 79; CIRS, Cumulative Illness Rating Scale; CLL, chronic lymphocytic leukemia; CLL-IPI, International Prognostic Index of CLL; DLBCL, diffuse large B-cell lymphoma; ECOG, Eastern Cooperative Oncology Group Performance Status (ECOG-PS); FISH, Fluorescende In Situ Hybridization; GCB, Germinal center B-cell-like; MUM-1, multiple myeloma oncogene 1 NOTCH1, neurogenic locus notch homolog protein 1; PAX-5, paired box protein 5; RT, Richter's Transformation; TP53, tumor protein p53; ZAP-70, zeta-chain-associated protein kinase 70.

clinical course of RT is aggressive with a reported median survival of 1-2 years. ${ }^{9-11}$

Risk factors for transformation may differ from risk factors for CLL progression. ${ }^{10}$ Therefore, RT may not necessarily be predicted from studies of CLL. Previous studies have identified that clinical (Binet stage B/C, performance status, lymphadenopathy), biochemical (lactate dehydrogenase elevation), biological (unmutated IGHV, expression of CD38 and ZAP70) and cytogenetic (del(13q) absence), (tri12), $\operatorname{del}(11 q)$ and $\operatorname{del}(17 p)$ factors are associated with an increased risk of RT (table 1). ${ }^{781012}$
Recently, studies have identified distinct genetic mechanisms by which CLL transforms into an aggressive lymphoma. Disruption of TP53, NOTCH1 and CDKN2A, as well as c-MYC activation were associated with development of RT. ${ }^{37}$

It is still controversial whether CLL therapy (purine-nucleoside analogue and/or targeted therapy) affects the risk of RT. ${ }^{811}$ Nevertheless, early transformation on targeted therapy is a concern for physicians as well as patients with aggressive CLL. ${ }^{13}$ As these patients may possibly benefit from alternative therapeutic strategies including intensive chemoimmunotherapy and allogeneic stem cell 
Patients with CLL/SLL registered in DCLLR, 2008-2016

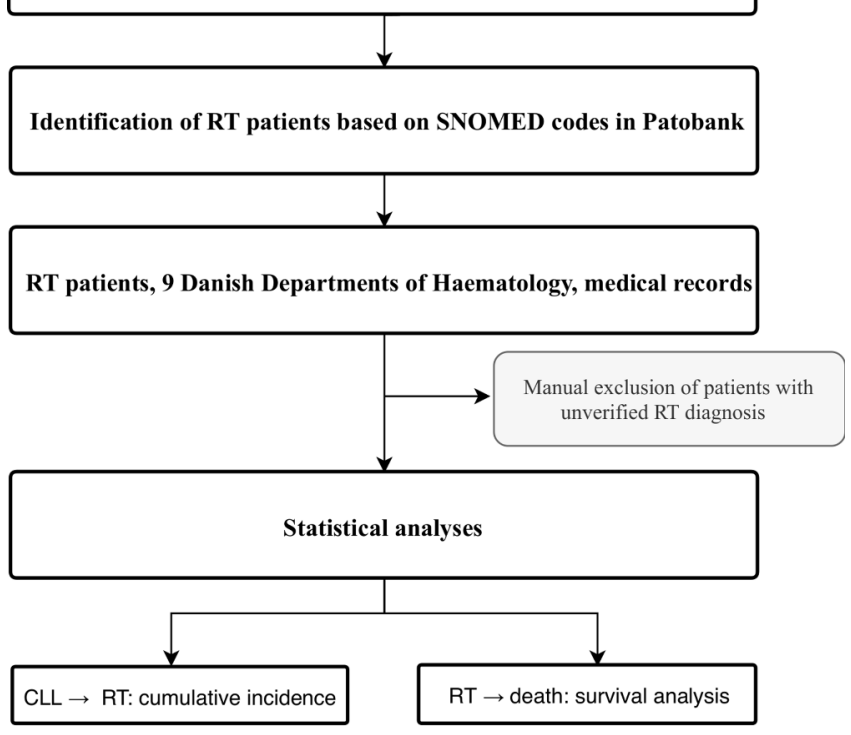

Figure 1 Flowchart of the study design. CLL, chronic lymphocytic leukemia; DCLLR, Danish National Chronic Lymphocytic Leukemia Registry; RT, Richter's transformation; SLL, small lymphocytic lymphoma; SNOMED, Systematized Nomenclature of Human Medicine.

transplantation, it is important to identify patients with increased risk of RT before initiating CLL therapy. ${ }^{12} 14$

\section{Research questions}

1. What is the incidence of Richter's transformation (RT) in a nationwide cohort?

2. Are we able to confirm risk factors already identified in previous studies?

3. Can we identify novel risk factors for development of RT?

4. Does treatment of chronic lymphocytic leukaemia affect development of RT?

5. How do these risk factors impact overall survival?

\section{METHODS AND ANALYSIS \\ Study design}

The study protocol for identification of patients with RT, data collections and data analyses are summarised in figure 1 .

\section{Patient identification}

All patients in the Danish CLL Registry (DCLLR) between 2008 and 2016 are included, since it is mandatory for all physicians to report CLL patients in this registry. The registry includes patients diagnosed with CLL according to the International Workshop on CLL (IWCLL) criteria, a Danish address and a valid personal identification number. Therefore, this registry comprises data on all patients diagnosed in Denmark, including date of birth, gender, date of death, treatment regimens and risk factors. ${ }^{713}$
Box 1 Systematized Nomenclature of Human Medicine (SNOMED) codes

M96503 Hodgkin's lymphoma.
M96512 Hodgkin's lymphoma, classical type, in incomplete remission.
M96513 Hodgkin's lymphoma, classical type.
M96518 Hodgkin's lymphoma, classical type, in remission.
M96523 Hodgkin's lymphoma, MC type.
M96533 Hodgkin's lymphoma, LD type.
M96593 Hodgkin's lymphoma, nodular lymphocyte predominant.
M96633 Hodgkin's lymphoma, NS type.
M96793 Mediastinal large cell B-cell lymphoma.
M96803 Diffuse large cell B-cell lymphoma.
M96823 Diffuse large cell B-cell lymphoma, immunoblastic variant.
M96833 Diffuse large cell B-cell lymphoma, T-cell/histiocytic variant.
M96853 Intravascular large cell B-cell lymphoma.
ÆEYYY0X Transformation.

Patients identified from DCLLR with a concomitant biopsy proven diagnosis of DLBCL and/or HL from the Danish National Pathology Data Bank (Patobank) is considered to have RT and will be included in this study. Patobank is a national histopathology and cytopathology register founded in 1978 and is now nationwide ${ }^{15}$ Systematized Nomenclature of Human Medicine codes included in this study are summarised in box 1 .

A strategy for collecting information on RT patients will consist of a double-controlled reading. Once the initial reading of a patient chart is completed, a second researcher will verify the collected data.

\section{Patients and public involvement}

Involvement of all Danish CLL patients will be ensured through nationwide registries. Since data will be collected in a retrospective manner, the CLL patients are unable to participate and engage directly in this current study. Our research results concerning risk factors for RT will broaden the understanding of RT among CLL patients. This may potentially cause national and local health changes, that directly responds to the concerns and real-life experiences of CLL patients. By gathering data, evidence and knowledge in this study, direct influence on the understanding of RT in CLL may modify national guidelines. New insights into the barriers of RT may develop approaches that researchers can use when handling additional aspects of CLL patients in risk of RT.

\section{Statistical analysis plan}

Patients will be followed from time of CLL diagnosis until death or end of follow-up, whichever comes first.

The statistical analysis in this study will be based on baseline characteristics where we will examine three time points.

1. In the time from CLL diagnosis to diagnosis of RT, risk factors will be investigated to determine their impact on RT (table 1). 
2. From time of initiating treatment to time of RT diagnosis, we will investigate the impact of CLL treatment on the risk of development of RT.

3. From RT diagnosis to death, we will measure the influence of the risk factors on the overall prognosis of RT.

Descriptive analysis of all possible risk factors (table 1) will be performed. For continuous variables, the mean, $\mathrm{SD}$ or median and IQR values will be reported according to distribution. The categorical data will be presented with frequency tables $(\mathrm{n}, \%)$.

The Aalen-Johansen estimator will be used for cumulative incidence. The Kaplan-Meier method will be used for overall survival. Log-rank and Gray's test will be used to test differences between groups.

CLL patients without RT obtained from the DCLLR will represent our control group. The data from this control group will be compared with data from RTpatients collected from Patobank.

Cox models for multivariable analysis will be performed with backward elimination. Statistical significance will be defined as a $p$ value of less than 0.05 . All data manipulation, visualisation and statistical analysis will be performed with $\mathrm{R}^{16}$

\section{DISCUSSION}

$\mathrm{RT}$ is one of the most severe complications of CLL. The previously published retrospective studies have identified clinical, biochemical, biological as well as genetic characteristics in CLL patients to be important risk factors for $\mathrm{RT}^{781011}$

Our study will be the first nationwide study to investigate the incidence of RT and analyse the impact of risk factors in multivariable analyses. Moreover, we will be able to assess if different treatment regimens are associated with higher risk of RT, thus answering important questions in our understanding of RT.

\section{Strengths}

The key strength of our study is the nationwide setup, with a consecutive cohort of more than 4000 CLL patients and a predefined analysis plan and protocol. The Danish unique identification number enables us to merge registry data to ensure a complete follow-up in an unselected real world CLL population. ${ }^{1718}$ We expect to find a total of 80-200 RT patients, enabling us to assess multiple factors for both risk of RT and survival following RT. In contrast, single centre studies often represent data with a risk of selection-bias towards a higher socioeconomic status, hence a healthier patient cohort. ${ }^{19}$ This cohort will ensure a high coverage of all patients diagnosed with CLL within a nine-year period, ${ }^{2}$ due to the cross validation of DCLLR with other registries.

Through a manual, double-controlled assessment of medical records, we will assess multiple risk factors in association to outcomes. The data assembly from medical records will ensure information on both patient-specific and disease-specific variables, as well as information on treatment variables and response to treatment. The crossed reading of the medical records ensures a complete data collection, minimising the amount of missing information.

With this approach, our outcomes are expected to add further evidence to existing knowledge on potential risk factors identified so far.

Investigation of the clonal relationship is of high clinical importance. Recent studies have shown that the clonal relationship between DLBCL and the underlying CLL has critical prognostic implications in RT. ${ }^{20}$ However, the question concerning clonal relationship between DLBCL cells and the pre-existing or concomitant CLL remains unanswered. In this respect, a possible follow-up study using tissue samples, will determine the prognostic impact of clonal status in RT patients.

Studies examining clonality and genetic associations to RT are therefore needed for novel treatment targets in patient at high risk of RT. We suggest implementing a high degree of screening and careful, long-term monitoring programmes to identify CLL patients harbouring relevant risk factors. High risk of RT may influence the patient counselling, making patients more aware of systemic symptoms which facilitates an early diagnosis of RT. By promptly detecting RT in these patients, we expect a more favourable prognosis.

\section{Limitations}

To address research questions in rare complications to rare cancers, prospective studies are not always feasible. Thus, knowledge concerning risk factors predicting RT in CLL patients is limited. Retrospective studies are therefore necessary to determine the risk factors. These studies are often susceptible to methodological bias and chance findings, which is also a major limitation in our study.

Even though DCLLR is highly validated, we cannot fully exclude selection bias in our study. ${ }^{17}$ We must consider that some departments have a more thorough registration than others, even though the cross validation with other health registries aim to minimise any selection bias.

Due to limited information on socioeconomic status as well as ethnical, dietary patterns and geographical differences, the impact of such on RT cannot be addressed in this study.

Despite the limitations, this protocol describes an approach to enable further testing of evidence concerning risk factors and outcomes of RT. We aim to establish clinically significant risk factors that can potentially guide the management of patients with CLL.

The results from this study may be used to create a risk model to stratify patients with RT into three prognostic groups; high, intermediate and low risk. Hereby, we can stratify patients with potential implications on medical practices. These results are expected to add further on potential risk factors identified so far.

Author affiliations

${ }^{1}$ Department of Hematology, Rigshospitalet, Copenhagen, Denmark 
${ }^{2}$ Department of Pathology, Rigshospitalet, Copenhagen, Denmark

Acknowledgements The authors would like to thank Casper Tabassum Eriksen for helping them to revise the English language of the manuscript.

Contributors Contributors MHH and YB-D will contribute equally to the study. The protocol was written by MHH and YB-D, and was revised by CDC-B, CB, EC-L, MAA and CUN. The study design is developed by MHH, YB-D, MAA and CUN, and will be performed by $\mathrm{MHH}$ and $\mathrm{YB}-\mathrm{D}$, who will also independently extract data from haematological departments across Denmark. MAA, MHH and YB-D will oversee the statistical analysis. CDC-B will provide the study with data of $4000 \mathrm{CLL}$ patients from DLCCR and thus offer a unique opportunity for population-based-research. CB will contribute with knowledge concerning genetic and biological markers. In relation to pathology, the search strategy to collect RT patients will be guided by EC-L. MAA and CUN will work collaboratively to arbitrate the disagreements and ensure that no errors are introduced during the study. All the authors critically revised the manuscript for important content and provided approval of the final version of the protocol to be published.

Funding This research received support from the Research Committee, Rigshospitalet, for undertaking this project.

Competing interests None declared.

Patient consent for publication Obtained.

Ethics approval The study was approved by the Danish Data Protection Agency and the Danish Health Authorities.

Provenance and peer review Not commissioned; externally peer reviewed.

Author note Further information can be obtained from the first authors.

Open access This is an open access article distributed in accordance with the Creative Commons Attribution Non Commercial (CC BY-NC 4.0) license, which permits others to distribute, remix, adapt, build upon this work non-commercially, and license their derivative works on different terms, provided the original work is properly cited, appropriate credit is given, any changes made indicated, and the use is non-commercial. See: http://creativecommons.org/licenses/by-nc/4.0/.

\section{REFERENCES}

1. Hallek M. Chronic lymphocytic leukemia: 2017 update on diagnosis, risk stratification, and treatment. Am J Hematol 2017;;92:946-65.

2. da Cunha-Bang $\mathrm{C}$, Geisler $\mathrm{CH}$, Enggaard L, et al. The danish national chronic lymphocytic leukemia registry. Clin Epidemiol 2016;8:561-5.

3. Rossi D, Gaidano G. Richter syndrome: pathogenesis and management. Semin Oncol 2016;43:311-9.

4. Parikh SA, Kay NE, Shanafelt TD. How we treat Richter syndrome. Blood 2014;123:1647-57.

5. Tadmor T, Shvidel L, Bairey O, et al. Richter's transformation to diffuse large B-cell lymphoma: a retrospective study reporting clinical data, outcome, and the benefit of adding rituximab to chemotherapy, from the Israeli CLL Study Group. Am J Hematol 2014;89:E218-E222.

6. Tsimberidou AM, O'Brien S, Khouri I, et al. Clinical outcomes and prognostic factors in patients with Richter's syndrome treated with chemotherapy or chemoimmunotherapy with or without stem-cell transplantation. J Clin Oncol 2006;24:2343-51.

7. Parikh SA, Shanafelt TD. Risk factors for Richter syndrome in chronic lymphocytic leukemia. Curr Hematol Malig Rep 2014;9:294-9.

8. Parikh SA, Rabe KG, Call TG, et al. Diffuse large B-cell lymphoma (Richter syndrome) in patients with chronic lymphocytic leukaemia (CLL): a cohort study of newly diagnosed patients. Br J Haematol 2013;162:774-82.

9. Vitale C, Ferrajoli A. Richter syndrome in chronic lymphocytic leukemia. Curr Hematol Malig Rep 2016;11:43-51.

10. Rossi D, Cerri M, Capello D, et al. Biological and clinical risk factors of chronic lymphocytic leukaemia transformation to Richter syndrome. Br J Haematol 2008;142:202-15.

11. Maddocks-Christianson K, Slager SL, Zent CS, et al. Risk factors for development of a second lymphoid malignancy in patients with chronic lymphocytic leukaemia. Br J Haematol 2007;139:398-404.

12. Fangazio M, De Paoli L, Rossi D, et al. Predictive markers and driving factors behind Richter syndrome development. Expert Rev Anticancer Ther 2011:11:433-42.

13. Ahn IE, Underbayev C, Albitar A, et al. Clonal evolution leading to ibrutinib resistance in chronic lymphocytic leukemia. Blood 2017;129:1469-79.

14. Niemann CU, Polliack A, Hutchings M. Suspected Richter transformation: positron emission tomography/computed tomography tells us who should have a biopsy and where. Leuk Lymphoma 2014;55:233-4.

15. Erichsen R, Lash TL, Hamilton-Dutoit SJ, et al. Existing data sources for clinical epidemiology: the Danish National Pathology Registry and Data Bank. Clin Epidemiol 2010;2:51-6.

16. Core Team R. R: A Language and Environment for Statistical Computing [Internet]. Vienna, Austria: R Foundation for Statistical Computing, 2018. https://www.R-project.org/.

17. Schmidt M, Schmidt SA, Sandegaard JL, et al. The Danish National Patient Registry: a review of content, data quality, and research potential. Clin Epidemiol 2015;7:449-90.

18. Pedersen CB. The Danish Civil Registration System. Scand J Public Health 2011;39(7 Suppl):22-5.

19. Biau DJ, Kernéis S, Porcher R. Statistics in brief: the importance of sample size in the planning and interpretation of medical research. Clin Orthop Relat Res 2008;466:2282-8.

20. Rossi D, Spina V, Deambrogi C, et al. The genetics of Richter syndrome reveals disease heterogeneity and predicts survival after transformation. Blood 2011;117:3391-401.

21. Grann AF, Erichsen R, Nielsen AG, et al. Existing data sources for clinical epidemiology: The clinical laboratory information system (LABKA) research database at Aarhus University, Denmark. Clin Epidemiol 2011;3:133-8. 